\title{
Percutaneous balloon pulmonary valvuloplasty
}

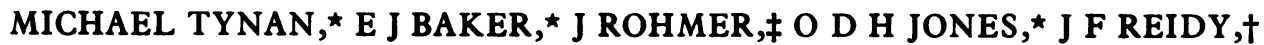 \\ $M$ C JOSEPH,, J OTTENKAMP¥
}

From the Departments of ${ }^{\text {Paediatric Cardiology and }+R a d i o l o g y, ~ G u y ' s ~ H o s p i t a l, ~ L o n d o n, ~ a n d ~ t h e ~} \ddagger$ Department of Paediatric Cardiology, Academisch Ziekenhuis, Leiden, The Netherlands

SUMmary Percutaneous pulmonary valvuloplasty was performed in 27 patients with congenital pulmonary valve stenosis. A fall in the transvalve gradient of at least $15 \mathrm{~mm} \mathrm{Hg}$ occurred in 22 patients. In five there was little change in the severity of the stenosis; in three of these the pulmonary valve was dysplastic. None of the successfully treated patients had a dysplastic valve. The two other failures, early in the series, were probably due to inadequate balloon size. In one patient the procedure was performed twice, with a successful result from the second dilatation with a larger balloon. Follow up studies in a further six patients showed no evidence of restenosis in those who had been successfully treated and no late improvement in the remainder. There were no important complications.

Percutaneous pulmonary valvuloplasty should be the initial treatment for congenital pulmonary valve stenosis, although when the valve is dysplastic the result is less likely to be satisfactory.

Much experience has been gained in the use of percutaneous balloon angioplasty for acquired peripheral vascular disease and also coronary artery disease. ${ }^{1-3}$ In addition, the technique has recently been used to treat various congenital lesions including valvar pulmonary stenosis, ${ }^{4-6}$ valvar aortic stenosis, ${ }^{7}$ coarctation, ${ }^{8}$ postoperative recoarctation, 9 and peripheral pulmonary artery stenosis. ${ }^{10}$ Here we report our experience with the technique in 27 patients with congenital pulmonary valve stenosis.

\section{Patients and methods}

Percutaneous balloon valvuloplasty was attempted in 27 patients with congenital pulmonary valve stenosis aged 6 days to 20 years (mean 5.9 years). One had undergone an open pulmonary valvotomy seven years before the procedure. None of the remainder had previously been treated surgically. All the patients had clinical evidence of moderate to severe pulmonary valve stenosis.

In five patients the procedure was performed under a general anaesthetic; in the remainder premedication

Requests for reprints to Professor Michael Tynan, Department of Paediatrics, Guy's Hospital, London SE1 9RT.

Accepted for publication 8 January 1985 with pethidine or morphine was supplemented, if necessary, with intravenous ketamine.

The right femoral vein was entered percutaneously and a sheath inserted. A cannula was inserted into the right femoral artery to monitor continuously the systemic arterial pressure. In one patient access was via a right brachial cutdown and in another via a left fermoral percutaneous puncture. Full diagnostic catheterisation was performed to confirm the diagnosis and exclude any additional malformations. Only patients with a right ventricular systolic pressure greater than $50 \mathrm{~mm} \mathrm{Hg}$ at rest were considered for valvuloplasty. Right ventricular cineangiography was performed in the anterior-posterior and lateral projections. The diagnosis of pulmonary valve stenosis was confirmed and the size of the pulmonary valve annulus measured. The external diameter of the catheter was used as a reference length to correct for magnification. The position of the pulmonary valve in relation to the spine in the anterior-posterior projection was noted.

A balloon dilatation catheter was selected once the size of the pulmonary valve annulus was known. In patients treated early in the series a catheter with a balloon 1 or $2 \mathrm{~mm}$ smaller in diameter than the annulus was chosen; in patients treated later a catheter with a balloon equal to or 1 to $2 \mathrm{~mm}$ greater than the annulus was preferred. We used either a Surgimed angioplasty balloon catheter (maximum inflation pres- 
sure approximately $10 \mathrm{~atm}$ ) or a Meditech balloon dilatation catheter (maximum inflation pressure approximately $3.5 \mathrm{~atm}$ ).

Optimally, an end-hole catheter was manipulated into the left pulmonary artery, and through it a $0.89 \mathrm{~mm}(0.035$ inch) exchange guide wire was advanced into the left lower lobe pulmonary artery. In three patients the guide wire could be anchored securely only in the right lower lobe pulmonary artery. The catheter was withdrawn, care being taken to maintain the position of the guide wire so that its tip remained well out in the pulmonary artery. The catheter and sheath were removed. A dilator equal to the external diameter of the uninflated balloon catheter was used to dilate the entry site. Once the balloon catheter had been tested and the balloon purged of air the balloon was deflated and inserted over the guide wire. For the smaller balloon sizes a sheath was used.

The balloon catheter was advanced until the estimated position of the pulmonary valve was at the centre of the balloon. The guide wire was left in place during the dilatation procedure. The balloon was then inflated to its maximum pressure with diluted contrast medium. In most cases an indentation at the site of the pulmonary valve was seen as the balloon was inflated. This was abolished as full inflation was achieved (Figure). The balloon was then rapidly deflated. The inflation-deflation cycle took 15 to 25 seconds. Before subsequent dilatations the position of the balloon was slightly adjusted if necessary. Between one and eight dilatations were performed in each case.

Suction was maintained on the balloon catheter as it was withdrawn through the skin at the groin. An end-hole catheter was then reinserted over the guide wire into the left pulmonary artery. The pulmonary artery and right ventricular pressures on withdrawal were recorded.

Clinical follow up took place one to six months after the procedure. Equilibrium gated radionuclide angiography was performed after the procedure in $\mathbf{1 0}$ patients. One patient required a repeat valvuloplasty. In six other patients repeat cardiac catheterisations were performed. In two this was because the initial procedure had been unsuccessful and further surgical treatment was indicated. The minimum time between the initial valvuloplasty and follow up catheterisation was two months.

\section{Results}

The transvalve gradient fell by at least $15 \mathrm{~mm} \mathrm{Hg}$ in 22 patients. This was accompanied by a substantial decrease in the right ventricular pressure in 21 patients. In one (case 24) the right ventricular pressure fell by only $10 \mathrm{~mm} \mathrm{Hg}$ but the pulmonary artery
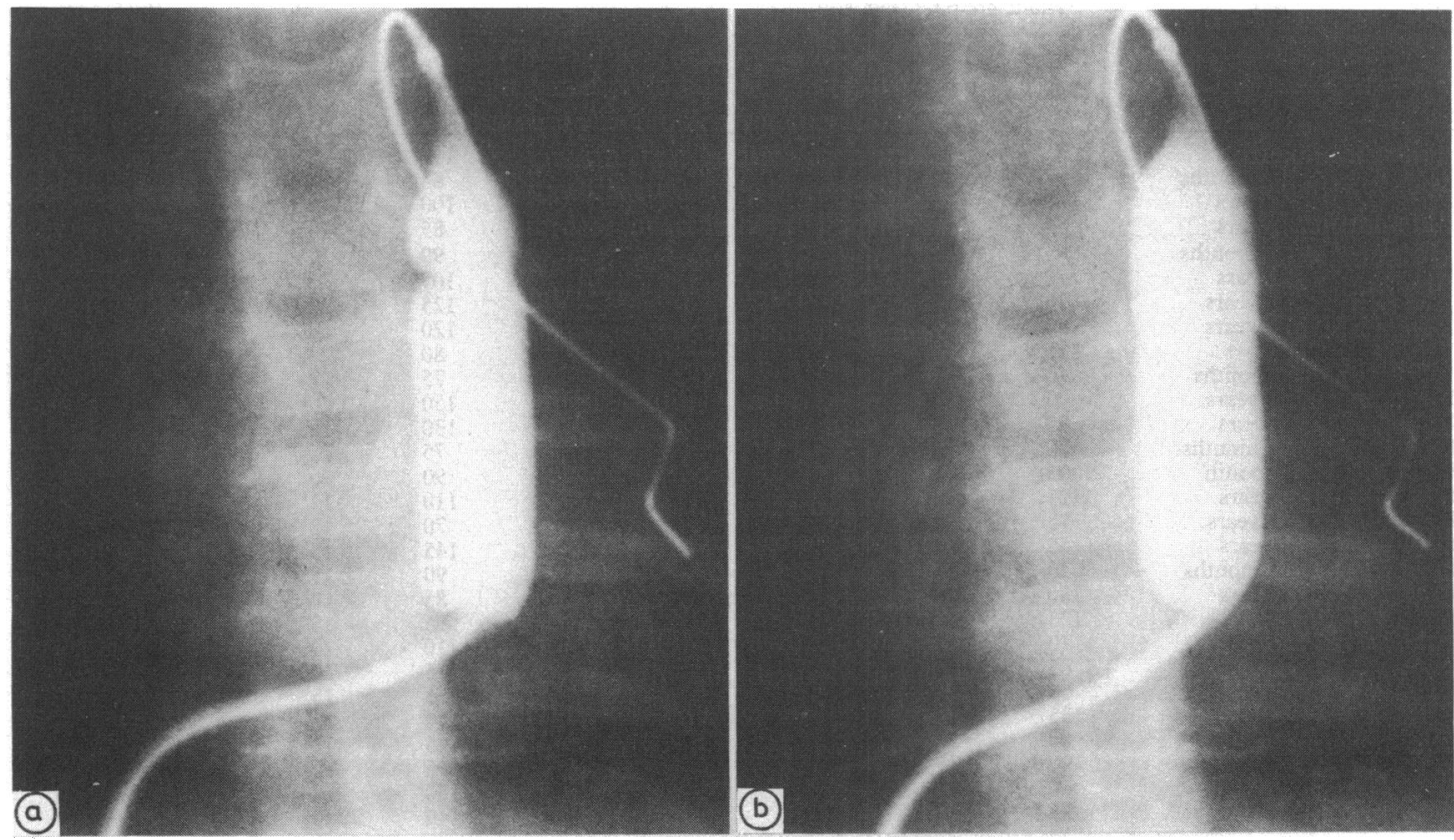

Fig. A balloon catheter (a) partially inflated while across a stenotic pulmonary valve (the balloon is indented by the valve) and $(b)$ fully inflated, when the indentation disappears. 
pressure rose, producing a fall from 35 to $15 \mathrm{~mm} \mathrm{Hg}$ in the gradient across the pulmonary valve. In five patients a satisfactory relief of the stenosis was not achieved. Of these five, one (case 9) had both valvar and subvalvar gradients, with a dysplastic valve. Two others (cases 6 and 13) also had dysplastic pulmonary valve leaflets as judged from the right ventricular angiograms. One of these two patients (case 6) had previously undergone an open pulmonary valvotomy. None of the patients in whom the outcome was successful was judged to have a dysplastic valve on the cineangiogram.

One child (case 5) underwent the procedure twice. During the first dilatation, early in the series, a $10 \mathrm{~mm}$ Surgimed balloon catheter was used. The measured diameter of the pulmonary valve annulus was $13 \mathrm{~mm}$. The right ventricular pressure fell from $65 \mathrm{~mm} \mathrm{Hg}$ to $55 \mathrm{~mm} \mathrm{Hg}$. Ten months later the right ventricular pressure was found to be $70 \mathrm{~mm} \mathrm{Hg}$ so repeat valvuloplasty was performed with a $12 \mathrm{~mm}$ Meditech balloon catheter. The right ventricular pressure fell to $40 \mathrm{~mm} \mathrm{Hg}$. Table 1 shows the haemodynamic results in all patients.

The mean (SD) ratio of systolic right ventricular to femoral artery pressure in all patients before dilatation was $0.81(0.39)$ and immediately after valvuloplasty
$0.47(0.17)$. Comparing these results by a paired $t$ test shows this to be a highly significant fall $(t=5 \cdot 22$, $p<0.001)$. The mean systolic pressure gradient from the right ventricle to the pulmonary artery before dilatation was $64.4(30.1) \mathrm{mm} \mathrm{Hg}$; after dilatation it fell to $27.0(12.1) \mathrm{mm} \mathrm{Hg}$. Again a paired $t$ test shows this to be a highly significant fall $(t=5.89, p<0.001)$.

In most patients the systemic blood pressure fell during the time the balloon was inflated. In one (case 2) there was no fall in the systolic blood pressure, even though a good result was achieved. The blood pressure rose again spontaneously in every case as the balloon was deflated. The longest period of hypotension was 50 seconds (case 12).

In 12 patients bradycardia developed during the balloon dilatation. This also was self limiting. One patient (case 13) developed complete heart block during the first dilatation with a ventricular rate of $\mathbf{4 0}$ beats/minute. This reverted spontaneously to normal conduction after 120 seconds. In this case the patient had a dysplastic valve; further dilatations were not attempted.

Two of the older patients who were not fully sedated during the procedure lost conciousness when the balloon was inflated, and one 3 year old patient (case 23) had a convulsion that stopped when the bal-

Table 1 Haemodynamic data from patients listed in chronological order

\begin{tabular}{|c|c|c|c|c|c|c|c|c|c|}
\hline \multirow{3}{*}{$\begin{array}{l}\text { Case } \\
\text { No }\end{array}$} & \multirow[t]{3}{*}{ Age } & \multicolumn{6}{|c|}{ Systolic pressures (min $\mathrm{Hg}$ ) } & \multirow{3}{*}{$\begin{array}{l}\text { Balloon } \\
\text { diameter } \\
(\mathrm{mom})\end{array}$} & \multirow{3}{*}{$\begin{array}{l}\text { Pulmonary } \\
\text { valoe } \\
\text { diameter } \\
\text { (mm) }\end{array}$} \\
\hline & & \multicolumn{3}{|c|}{ Before } & \multicolumn{3}{|c|}{ After } & & \\
\hline & & $R V$ & $P A$ & $F A$ & $R V$ & $P A$ & $F A$ & & \\
\hline $\begin{array}{l}\left.\begin{array}{l}1 \\
2 \\
3 \\
4 \\
5\end{array}\right\} \text { 1st } \\
6 \\
7 \\
8 \\
9 \\
10 \\
11 \\
12 \\
13 \\
14 \\
15 \\
16 \\
17 \\
18 \\
19 \\
20 \\
21 \\
22 \\
23 \\
24 \\
25 \\
26 \\
27\end{array}$ & $\begin{array}{l}11 \text { years } \\
16 \text { months } \\
3 \text { years } \\
3 \text { years } \\
16 \text { months } \\
2 \text { years } \\
17 \text { years } \\
12 \text { years } \\
6 \text { days } \\
5 \text { months } \\
20 \text { years } \\
7 \text { years } \\
16 \text { months } \\
1 \text { month } \\
2 \text { years } \\
11 \text { years } \\
4 \text { years } \\
13 \text { months } \\
5 \text { years } \\
6 \text { years } \\
12 \text { years } \\
14 \text { years } \\
7 \text { years } \\
3 \text { years } \\
9 \text { months } \\
4 \text { years } \\
10 \text { years } \\
8 \text { years }\end{array}$ & $\begin{array}{r}65 \\
75 \\
60 \\
55 \\
65 \\
70 \\
80 \\
90 \\
110 \\
70 \\
70 \\
95 \\
70 \\
95 \\
125 \\
75 \\
65 \\
70 \\
180 \\
125 \\
70 \\
85 \\
60 \\
135 \\
60 \\
90 \\
60 \\
75\end{array}$ & $\begin{array}{l}20 \\
20 \\
25 \\
18 \\
20 \\
15 \\
10 \\
30 \\
15 \\
15 \\
20 \\
20 \\
15 \\
15 \\
30 \\
25 \\
16 \\
16 \\
9 \\
18 \\
12 \\
22 \\
30 \\
15 \\
25 \\
25 \\
17 \\
20\end{array}$ & $\begin{array}{r}125 \\
85 \\
100 \\
90 \\
90 \\
90 \\
115 \\
140 \\
85 \\
70 \\
155 \\
120 \\
75 \\
90 \\
135 \\
105 \\
110 \\
90 \\
75 \\
105 \\
125 \\
150 \\
130 \\
110 \\
125 \\
110 \\
90 \\
125\end{array}$ & $\begin{array}{l}40 \\
40 \\
45 \\
50 \\
55 \\
40 \\
60 \\
32 \\
45 \\
60 \\
50 \\
28 \\
35 \\
90 \\
45 \\
35 \\
65 \\
50 \\
50 \\
55 \\
50 \\
35 \\
35 \\
35 \\
50 \\
50 \\
35 \\
50\end{array}$ & $\begin{array}{l}15 \\
20 \\
25 \\
15 \\
18 \\
18 \\
10 \\
25 \\
25 \\
15 \\
20 \\
20 \\
15 \\
28 \\
15 \\
22 \\
18 \\
10 \\
20 \\
12 \\
18 \\
20 \\
15 \\
35\end{array}$ & $\begin{array}{r}110 \\
85 \\
100 \\
85 \\
90 \\
105 \\
125 \\
120 \\
80 \\
75 \\
150 \\
130 \\
75 \\
90 \\
110 \\
70 \\
145 \\
90 \\
85 \\
95 \\
110 \\
135 \\
125 \\
110 \\
115 \\
95 \\
100 \\
140\end{array}$ & $\begin{array}{c}12 \\
7-9 \\
9 \\
10 \\
10 \\
12 \\
20 \\
20 \\
7 \\
7 \\
20 \\
15 \\
15 \\
10 \\
12 \\
12 \\
15 \\
15 \\
18 \\
15 \\
20 \\
20 \\
15 \\
12 \\
12 \\
12 \\
20 \\
20\end{array}$ & $\begin{array}{r}13 \\
10 \\
16 \\
12 \\
13 \\
13 \\
24 \\
19 \\
8 \\
11 \\
22 \\
14 \\
14 \\
10 \\
13 \\
12 \\
14 \star \\
14 \\
16 \\
14 \\
20 \\
18 \\
15 \\
13 \\
12 \\
12 \\
19 \\
19\end{array}$ \\
\hline
\end{tabular}

^Echocardiographic measurement.

RV, right ventricle; PA, pulmonary artery; FA, femoral artery. 
loon was deflated. The convulsion recurred during subsequent dilatations.

No patient showed any neurological sequelae after pulmonary balloon valvuloplasty. Local complications at the puncture site did not develop in any patient. All patients were discharged from hospital within four days except one infant, in whom the procedure had failed, who underwent surgical valvotomy.

On clinical follow up the quality of the murmur was judged to have changed in most of the successful cases. Clinical evidence of pulmonary incompetence was not found in any patient. Analysis of the equilibrium gated radionuclide angiograms showed that the mean (SD) radionuclide ratio of left ventricular to right ventricular stroke counts was $1 \cdot 2(0 \cdot 2)$. A ratio of less than 0.7 indicates right ventricular volume overload. ${ }^{11}$ No patient fell into that category.

Follow up studies showed that in the four patients judged to have a good immediate result the fall in right ventricular pressure was maintained. In two other patients, who had poor immediate results, there was no late fall in right ventricular pressure (Table 2).

Table 2 Follow up data on six patients

\begin{tabular}{llll}
\hline Case & \multicolumn{3}{l}{ Systolic pressures $(\mathrm{mm} \mathbf{H g})$} \\
\cline { 2 - 4 } No & $\boldsymbol{R} V$ & $\boldsymbol{P A}$ & $\boldsymbol{F A}$ \\
\hline 1 & 45 & 22 & 125 \\
3 & 45 & 25 & 105 \\
6 & 75 & 15 & 125 \\
7 & 55 & 35 & 150 \\
8 & 40 & 15 & 85 \\
9 & 100 & 20 & 70 \\
\hline
\end{tabular}

$\mathrm{RV}$, right ventricle; PA, pulmonary artery; FA, femoral artery.

\section{Discussion}

The results presented here together with previous published reports of percutaneous balloon pulmonary valvuloplasty ${ }^{4-612}$ indicate that it can be an effective short term treatment for most patients with congenital pulmonary valve stenosis, including the newborn.

No major complications of the technique have been reported, and in most cases the right ventricular pressure has fallen sufficiently after the procedure to preclude the need for further treatment. There is no clinical evidence that pulmonary regurgitation is caused by the procedure, and in our patients radionuclide studies did not show evidence of right ventricular volume overload. These results compare favourably with those from open pulmonary valvotomy, where the postoperative right ventricular pressure is often $40 \mathrm{~mm} \mathrm{Hg}$ or more and pulmonary incompetence often occurs. ${ }^{13}$

It is not certain as yet how the valves subjected to balloon valvuloplasty are torn. In one case treated under direct vision in our unit during surgery the valve was split along a fused commissure, but Lababidi and $W u$ have reported a case in which a bicupsid valve was torn into the cusp tissue itself. 5

The physical principles of the dilatation of stenoses with balloons indicate that to apply the maximum dilating force to the stenotic lesion the biggest balloon feasible should be used. ${ }^{14}$ This consideration led us to prefer a balloon equal to or slightly larger than the pulmonary valve annulus for the patients treated later in our series. Though we used balloons with both high and low maximum inflation pressures, our data are insufficient to judge whether better results are obtained with the high inflation pressure balloon.

Generally the best results in our series of patients were seen in those with the highest initial right ventricular pressure. In those with lower pressures the results were not so dramatic, and follow up studies will be essential in judging the success of the technique. Of the six patients restudied, the four who had had a good immediate result had maintained the lower right ventricular pressure. There was no late fall in the two others, in whom the initial result was unsatisfactory.

Results were unsatisfactory in five of our patients. In three the valve was dysplastic. Such valves may not be amenable to this form of treatment. ${ }^{4}$ Indeed, we have not seen a successful outcome in any patient who appeared to have a dysplastic valve on cineangiography. In one of these three there was, in addition, a subvalvar obstruction, which despite being entirely muscular did not regress after the valvuloplasty. Two of these patients with dysplastic valves subsequently underwent surgery. Although the valve cusps in these patients were found to be thick and immobile, they were not fused. It is therefore not suprising that the balloon dilatation did not improve their function.

In the two other patients in whom treatment was unsatisfactory we believe that the balloon used may have been too small. In one we had for technical reasons to rely on an echocardiographic measurement of the size of the pulmonary valve annulus. In our experience this has been less satisfactory than an angiographic measurement. In the other (case 4), treated early in the series, we used a $10 \mathrm{~mm}$ balloon for a measured $12 \mathrm{~mm}$ pulmonary valve annulus. We would now consider a balloon of at least $12 \mathrm{~mm}$ essential. Similarly, in case 5 the first dilatation with a $10 \mathrm{~mm}$ balloon was unsuccessful, while a subsequent dilatation with a $12 \mathrm{~mm}$ balloon produced an appreciable fall in right ventricular pressure.

Two of our patients lost consciousness during the procedure, and one had convulsions. To protect patients from a potentially unpleasant experience we recommend that they are all effectively anaesthetised before balloon dilatation is attempted. We have gen- 
erally used ketamine anaesthesia. We would also recommend that each patient is given oxygen to breathe by face mask and that a prophylactic dose of atropine is administered before the dilatation is begun.

Experience to date indicates that percutaneous balloon valvuloplasty is safe, effective, and can be performed at any age. The limiting factor is judgment of the balloon size to be used. We believe that our recent, more aggressive approach is achieving better results. Although hard and fast indications have not yet been established, it is currently our treatment of choice for congenital pulmonary valve stenosis. When the valve is dysplastic the procedure is not as successful, but at present we would still recommend that balloon valvuloplasty should be the initial choice of treatment.

EJB is supported by the British Heart Foundation. We thank Mr P B Deverall for reporting his findings during surgery in these patients.

\section{References}

1 Grüntzig A. Transluminal dilatation of coronary-artery stenosis [Letter]. Lancet 1978; i: 263.

2 Petch MC. Unblocking coronary arteries. $\mathrm{Br} \mathrm{Med} \mathcal{J}$ 1982; 284: 683-4.

3 Katzen BT. Percutaneous transluminal angioplasty for arterial disease of the lower extremities. $A f R$ 1984; 142: 23-5.

4 Kan JS, White RI Jr, Mitchell SE, Anderson JH,
Gardner TJ. Percutaneous transluminal balloon valvuloplasty for pulmonary valve stenosis. Circulation 1983; 69: $554-60$.

5 Lababidi Z, Wu JR. Percutaneous balloon pulmonary valvuloplasty. Am F Cardiol 1983; 52: 560-2.

6 Rocchini AP, Kveselis DA, Crowley D, Dick M, Rosenthal A. Percutaneous balloon valvuloplasty for treatment of congenital pulmonary valvular stenosis in children. F Am Coll Cardiol 1984; 3: 1005-12.

7 Lababidi Z, Wu JR, Walls JT. Percutaneous balloon aortic valvuloplasty: results in 23 patients. Am $\mathcal{F}$ Cardiol 1984; 53: $194-7$.

8 Lock JE, Bass JL, Amplatz K, Fuhrman BP, Castaneda-Zuniga $W$. Balloon dilation angioplasty of aortic coarctations in infants and children. Circulation 1983; 68: 109-16.

9 Kan JS, White RI Jr, Mitchell SE, Farmlett EJ, Donahoo JS, Gardner TJ. Treatment of restenosis of coarctation by percutaneous transluminal angioplasty. Circulation 1983; 68: 1087-94.

10 Lock JE, Castaneda-Zuniga WR, Fuhrman BP, Bass JL. Balloon dilation angioplasty of hypoplastic and stenotic pulmonary arteries. Circulation 1983; 67: 962-7.

11 Parrish MD, Graham TP Jr, Born ML, et al. Radionuclide stroke count ratios for assessment of right and left ventricular volume overload in children. Am $\mathcal{F}$ Cardiol 1983; 51: 261-4.

12 Pepine CJ, Gessner IH, Feldman RL. Percutaneous balloon valvuloplasty for pulmonic valve stenosis in the adult. Am F Cardiol 1982; 50: 1442-5.

13 Nugent EW, Freedom RM, Nora JJ, Ellison RC, Rowe RD, Nadas AS. Clinical course in pulmonary stenosis. Circulation 1977; 56 (suppl 1): 38-47.

14 Abele JE. Balloon catheters and transluminal dilatation: technical considerations. $A \mathcal{R}$ 1980; 135: 901-6. 